\title{
Institutional Delivery Service Utilization and Associated Factors Among Women Who Delivered within the Last 2 Years in Waka Town, Maraka Woreda, Dawuro Zone, Southern Nation Nationalities Peoples Region, 2020
}

\author{
Mikias Zelalem ${ }^{1} \quad$ Tesfa Gebeyehu ${ }^{1} \quad$ Darulo Kurkura $^{1} \quad$ Damene Darota Amamo $^{2}$ \\ 1.Dawuro Tarcha Campus, Health Officers, School of Public Health, College of Medicine and Health Sciences, \\ Wolaita Sodo University, Ethiopia www.wsu.edu.et \\ 2.Dawuro Tarcha Campus, Lecturer, Department of Public Health, School of Public Health, College of \\ Medicine and Health Sciences, Wolaita Sodo University, Ethiopia www.wsu.edu.et
}

\begin{abstract}
Background: Globally, around 13.6 million maternal deaths occurred in the last 25 years. Ethiopia accounts one of the highest global maternal deaths, with more than $50 \%$ of births taking place at home. Hence, the aim of this study was to determine institutional delivery utilization in Waka town.

Objective: To determine the prevalence of institutional delivery and understand the factors associated with it in Waka town, Maraka wereda, Dawuro zone SNNPR.

Methodology: A community based cross sectional study is the study design chosen. The study was conducted, on mothers having a history of at least 1 birth within the last 2 years, who was selected by a systemic random sampling $(\mathrm{K}=2)$, from both Waka kebeles, which is selected by a simple random sampling from the 2 kebeles in the study area. For data collection, an interview with questioner containing both closed and open ended questions, along with non-participant observation method was employed. For analysis, Descriptive statistics, along with bivariate and multivariate analytical method was computed. Statistical significance was considered at $\mathrm{p}<0.05$, and the strength of statistical association was assessed by odds ratio (OR) with $95 \%$ confidence interval.

Result and Conclusion: The prevalence of institutional delivery service utilization in Waka town was found to be $89.4 \%$. Educational, economic and marital status of the mother, distance, health education provision, intendedness of the pregnancy, ANC follow up, and Knowledge of birth complications have shown significant association.
\end{abstract}

Keywords: Waka town, institutional delivery

DOI: $10.7176 / \mathrm{JHMN} / 93-01$

Publication date:September $30^{\text {th }} 2021$

\section{Introduction}

Globally, around 13.6 million maternal deaths occurred only in the last 25 years, and Ethiopia is one of the few countries which accounted for most of the global maternal deaths [1]. Low institutional delivery is considered to attribute significantly to high maternal mortality results in many countries, particularly in low income countries. In contrast, in SSA, where the burden of maternal mortality is the highest, only $57 \%$ of deliveries take place at health facilities [2] as compared to a large proportion of babies $(>98 \%)$ are delivered in health facilities in high income countries.

In Ethiopia still more than $50 \%$ of births continue to occur at home, with unskilled attendants [3]. Ethiopia was ranked as the lowest in the world as the average skilled birth attendance for developing countries is $59 \%$, which makes it hard for the country to achieve the maternal health goals set by itself as well as the SDG3 [2]. Other different studies have also came up with different institutional delivery service utilization prevalence results, which are all low and range from $4 \%-51.1 \%$ in Ethiopia $[3,19-20,21,24-27,23]$ and $6.2 \%-47.6 \%$ in SNNPR [28-29].

Several studies confirmed there are a lot of factors that affect the likelihood of a mother's institutional delivery service utilization include; illiteracy, poverty, distance from a health facility, parity, household decision maker etc. But there is a wide contextual difference concerning the type of associated factors and the significance of each of those factors on institutional delivery utilization [5-9].

The country has a long way to go, and a lot of work to do, if it is to achieve the SDG3, as well as its own set goals on improving maternal health. Knowing the current magnitude of the problem and the underlying factors affecting the issue can help to understand how successful previous works have been, and how much more work is required.

The importance of contextual based local studies at lower administrative levels understand the context specific local problems affecting mother's care seeking behavior in that particular area. So then, intervention programs that could meet the need in the specific locality can be designed. As such; this study assessed the prevalence of institutional delivery utilization and the associated factors in Waka town, Maraka woreda 
Methodology

Study area : The study was conducted in Waka town, Dawro Zone, SNNPR. Waka is a town in southwest Ethiopia, and is the urban center of Mareka woreda. Mareka is located 500KMs south west of Addis Ababa, the capital city of Ethiopia and two roads connect it to the outside world, one to Chida 73 kilometers in length and the other to Sodo 75 kilometers long.

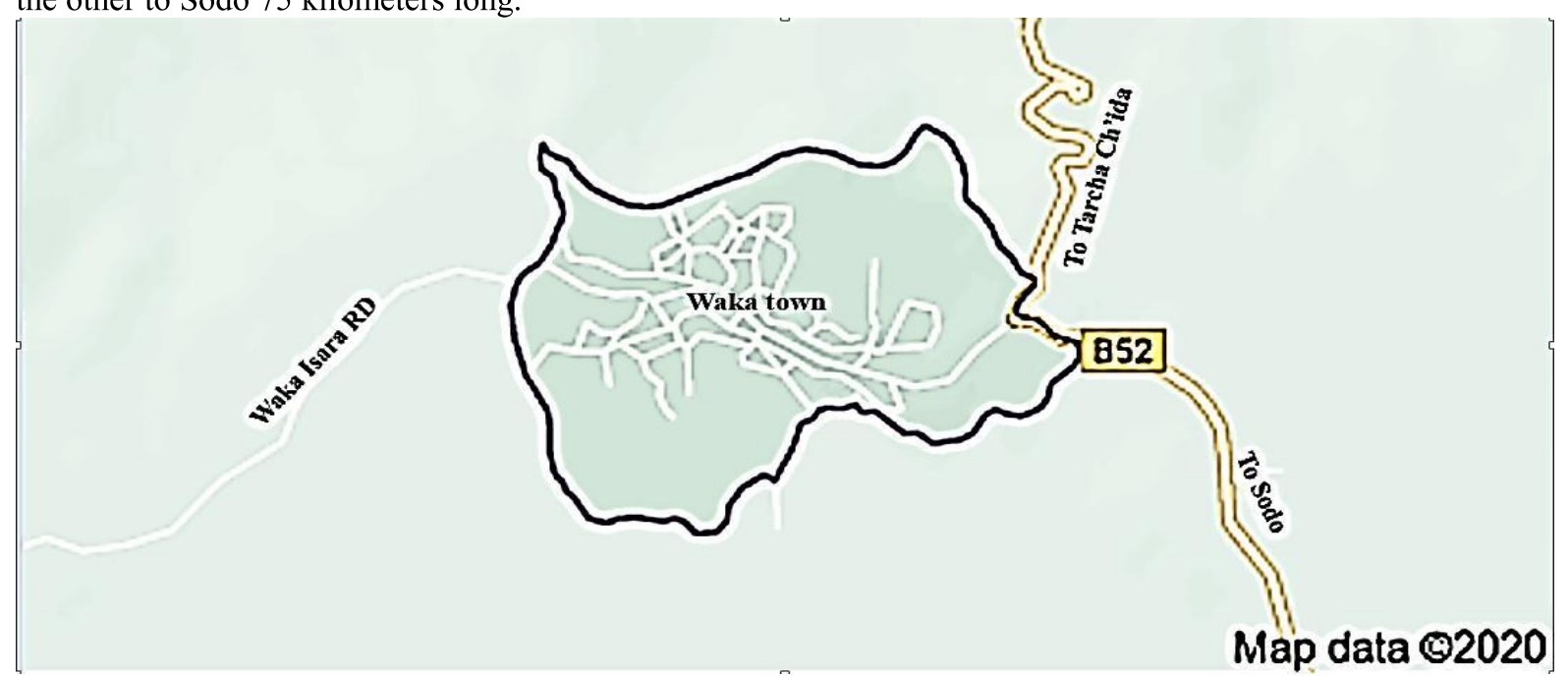

Figure 1: Showing the map of the study site

Based on figures from Maraka woreda municipality, Waka has an estimated total population of 45,303, of whom 22,198 are men and 23,104 are women. Additionally, it has two kebeles, namely; kebele 01, and kebele 02 , and within the town there is only one Health center (Waka health center).

A community based cross sectional study was employed. The study was conducted from November first 2020 G.C to January thirtieth of 2021 G.C. The study population was all child bearing women, who gave birth within the last one year in Waka town. The inclusion criteria were: Woman who gave birth after 28 weeks of pregnancy from the last menstrual period which includes, those who had still births, and neonatal deaths, within 12 months preceding the study. Woman who gave birth before their $28^{\text {th }}$ week of pregnancy and woman who had an abortion excluded from the study.

\section{Sample size determination}

Single population proportion was used based on the assumption of $\mathrm{P}$ value $=0.88$ (taken from a study done in Tigray [12]), margin of error 5\%, confidence level $95 \%$, and $10 \%$ non-response rate. $n=\frac{(z)^{2} \times p(1-p)}{d^{2}}$

$n=\frac{(1.96)^{2} \times 0.88(0.12)}{(0.05)^{2}}$

$n=\frac{(3.84) \times(0.11)}{0.0025}$

$n=163$

$10 \%$ NR were considered \&added the final sample size was 180 


\section{Sampling technique}

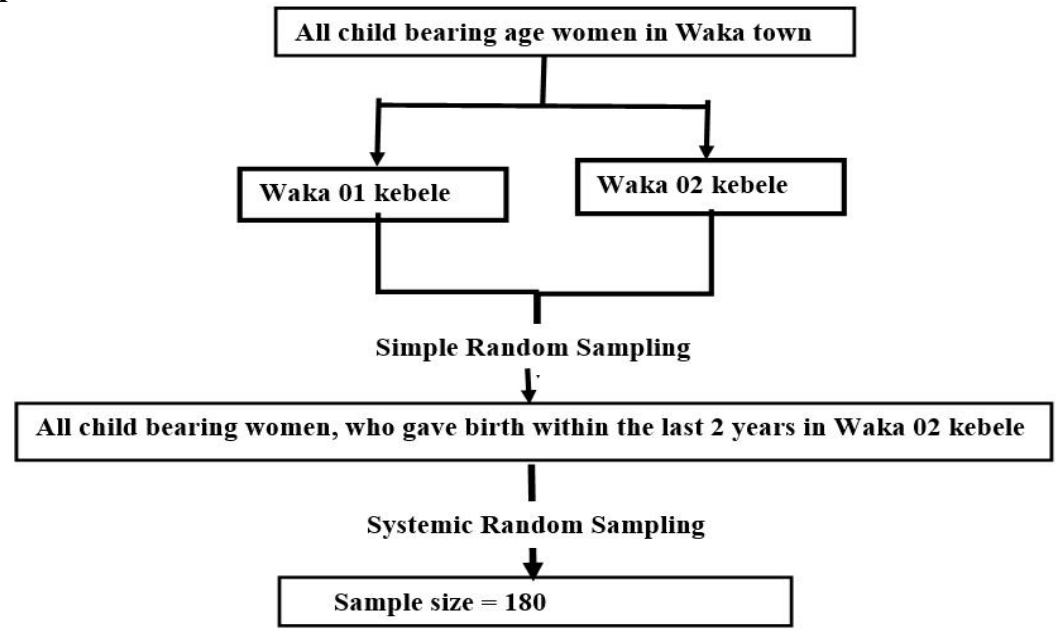

Figure 2: Showing the study sampling technique

Data collection procedures: Data was collected through face to face interview. Interviews were made using structured and pre-tested questionnaires, prepared in English which was translated to Amharic language for convenience. The questionnaire was contain questions concerning demographic and economic conditions, health information access, and obstetric history related factors that have been suggested by several studies for having effect on utilization of institutional delivery. Tape recorders was used to allow the respondents express any other missed factors in the questionnaire that affected their decision, to or to not to utilize a facility, and for this part of the interview.

Aside from questionnaires, a non-participant observation method was also be employed, mainly to determine health facility availability, quality, and its distance, and also to make sure the accuracy of information obtained from the participants.

Data quality assurance: To assure the quality of the data, orientation to the interviewers was provided by field supervisor about questionnaire, and observational methods to avoid respondent bias. The questionnaire was adopted from studies done on similar topic, and modified as necessary based on supervisor's review. And the collected data was revised by the supervisor and the investigators prior to analysis for its completeness, accuracy, and clarity.

Data analysis procedures: Data was statistically analyzed using SPSS version 20. It was described, summarized and presented using tables and graphs. Additionally, binary and multivariable logistic regression analyses were computed to examine the adjusted association between the outcome variable and the independent variables. Variables significant at the 5\% significance level $(\mathrm{P}<0.05)$ were retained and reported along with their adjusted odds ratio (AOR), and corresponding 95\% confidence interval (CI).

\section{Variables}

Dependent variables

- Institutional delivery service utilization.

\section{Independent variables}

- Predisposing factors: Age, educational status, occupational status, parity, household decision maker, cultural beliefs, information accessibility, maternal knowledge, attitude towards facility delivery, ethnicity, religion, and marital status,

- Enabling factors: Income, place of residence, quality of services, and distance,

- Need factors: ANC service utilization, pregnancy wantedness, birth preparedness, and previous experience of difficult child birth.

\section{Operational definitions}

- Knowledge: based on correct responses to the knowledge questions; respondents who know about the risks of pregnancy, and the importance of institutional maternal services. Those who answer $>75 \%$ of correct knowledge question was classified as well, $50 \%-75 \%$ fair, and $<50 \%$ as poor.

- Far from health facility: If travelled $\geq 30$ min walking to reach health care facility.

- Skill birth attendance: having an accredited health professional, including a midwife, doctor, or nurse, who has been trained in the skills needed to manage uncomplicated, and notice at the least complicated pregnancy and childbirth. 
- Institutional delivery: means any delivery at health facility (Hospital or health center).

- Woman's autonomy: If a woman decided on the place to give birth by herself or with her husband jointly.

Ethical considerations: Ethical clearance was obtained from Wolaita Sodo University Dawuro Tarcha campus Institutional Review Board (IRB). Permission paper was obtained from the Zonal, and the Maraka wereda health department, confirming there is no known risk posed by the study to the study participants, or the study area. The questionnaire contains no names and anything that can identify the study participants. Instead of name, code was used. Informed consent was obtained from each study participant and they was disclosed as it is their right to participate or not.

Dissemination plan: The results will presented in a symposium, in the presence of peer students, instructors, possibly local authorities and other relevant bodies. And again, the results, and recommendations was disseminated to the local authorities and other relevant bodies as much as possible and relevant. Moreover, efforts were made to publish in scientific health journals.

\section{Results}

\section{Socio Demographic Characteristics}

In this study, 180 mothers who have a history of at least one delivery within the last two years were included, out of which all 180 were successfully interviewed, with a respondent rate of $100 \%$. The mean age of the respondents was 26.65 years $( \pm 3.9 \mathrm{SD})$, and the age of most; $101(56.1 \%)$ of the mothers was between the ranges of 25-29. Majority of the respondents, $76(42.2 \%)$ of the mothers were with educational history of secondary level \& $81(45 \%)$ of the respondents were government employees [Table 1].

Regarding marital status, majority; $176(97.8 \%)$ of the mothers were married, $1(0.65)$ were divorced, and 3 $(1.7 \%)$ were unmarried. Out of the married 176 women, the husbands of $8(4.5 \%)$ cannot read and write, while the husbands of $70(39.8 \%)$ had an educational history of first degree and above. The husbands of all $176(100 \%)$ married women had a job, out of which majority; 91 (51.7\%) were government employees, $66(37.5 \%)$ had private jobs, and $19(10.8 \%)$ were farmers. Concerning spousal age, the husbands of most; $100(56.8 \%)$ of the married women were between the ranges of 25-34. And, most $95(52.85 \%)$ of the interviewed women had a family monthly average income of more than 5000, while 47 (26.1\%) of the respondents had a family monthly average income of less than 1000 [Table 1].

Table 1: showing the socio demographic characteristics of mothers $(n=180)$ in Waka town, SNNPR-2020.

\begin{tabular}{|c|c|c|c|}
\hline Variable & Category & Frequency & Percentage \\
\hline \multirow[t]{4}{*}{ Ethnicity } & Dawuro & 169 & 93.9 \\
\hline & Wolaita & 8 & 4.4 \\
\hline & Amhara & 1 & 0.6 \\
\hline & Oromo & 2 & 1.1 \\
\hline \multirow[t]{3}{*}{ Religion } & & 119 & 66.1 \\
\hline & Protestant & 61 & 33.9 \\
\hline & Orthodox & & \\
\hline \multirow[t]{6}{*}{ Age } & & 3 & 1.7 \\
\hline & $15-19$ & 36 & 20 \\
\hline & $20-24$ & 101 & 56.1 \\
\hline & $25-29$ & 30 & 16.7 \\
\hline & $30-34$ & 10 & 5.6 \\
\hline & $35-39$ & & \\
\hline \multirow[t]{5}{*}{ Educational status } & & 10 & 5.6 \\
\hline & Illiterate & 44 & 24.4 \\
\hline & Primary school & 76 & 42.2 \\
\hline & Secondary school & 50 & 27.8 \\
\hline & $1^{\text {st }}$ degree and above & & \\
\hline \multirow[t]{5}{*}{ Occupational status } & & 56 & 31.1 \\
\hline & Housewife & 81 & 45 \\
\hline & Government employee & 41 & 22.8 \\
\hline & Private worker & 2 & 1.1 \\
\hline & Student & & \\
\hline \multirow{4}{*}{ Average monthly income } & & 47 & 26.1 \\
\hline & $<1000$ & 38 & 21.1 \\
\hline & $1000-5000$ & 95 & 52.8 \\
\hline & $>5000$ & & \\
\hline
\end{tabular}




\begin{tabular}{llcc}
\hline Marital status & Married & 176 & 97.8 \\
& Divorced & 1 & 0.6 \\
& Unmarried & 3 & 1.7 \\
Spousal Educational status (176) & & & 4.5 \\
& Illiterate & 8 & 11.4 \\
& Primary school & 20 & 44.3 \\
& Secondary school & 78 & 39.8 \\
Spousal Occupational status & 1 $^{\text {st degree and above }}$ & 70 & 51.7 \\
(176) & & & 37.5 \\
& & 91 & 10.8 \\
Spouse's age & Government employee & 66 & 7.4 \\
& Private worker & 19 & 56.8 \\
\hline
\end{tabular}

\section{Obstetric Related Characteristics}

Among the study participants, $130(72.2 \%)$ of the mothers were multiparous/ have had more than one child delivery experience, out of whom, majority; 94 (72.3\%) have had 1-2 previous deliveries, while only $2(1.5 \%)$ mothers have had 5 or more than 5 previous deliveries. Out of all the multiparous mothers, $101(77.7 \%)$ of the mothers delivered all of their previous children at a health facility, while $15(11.5 \%)$ of the mothers delivered all of their previous children at home. $97(74.6 \%)$ of the multiparous mothers have never had any delivery related complications during their previous child deliveries, while $33(25.4 \%)$ have had previous experiences of delivery related complications [Table 2].

The most recent pregnancies of most; $159(88.3 \%)$ of the respondents occurred intentionally, while the pregnancies of the rest were unintended. During those pregnancies, all $180(100 \%)$ of the respondents were prepared for delivery, and $163(90.6 \%)$ of them had at least one ANC follow up visit. $47(26.1 \%)$ of the respondents have had experienced pregnancy related complications during their recent pregnancies. Majority, $159(88.3 \%)$ of the women decided their place of child delivery together with their husbands [Table 2]. The last child delivery of $161(89.4 \%)$ of the respondents occurred at a health institution. And, out of the $19(10.6 \%)$ mothers who had their last delivery at home, 7 (36.8\%) mentioned tradition, and previous safe home delivery experiences to be the reason for their home delivery, the other $7(36.8 \%)$ mentioned long distance residence from health institution in association with lack of transport. And, out of the 161 mothers who utilized health facilities for their last delivery, $113(70.2 \%)$ were very satisfied with the service they received [Table 2]. Concerning knowledge of birth complications, $126(70 \%)$ of the studied mothers were knowledgeable, and were able to mention at least one major possible complication of birth. And, all $180(100 \%)$ of the respondents had favorable attitude towards institutional delivery.

During the survey interview all the respondents were asked to mention all the possible reasons in their knowledge, about why women in their area, other than themselves may prefer to deliver at home, for which the most mentioned answers are presented in this result.Majority, $109(60.6 \%)$ of the respondents responded with; lack of education and awareness, which most explained with lack of modern education, and lack of HEWs reachability to all, because HEWs tend to focus on the community living at the center of the town, the other most mentioned answer was unprecedented labor without enough preparation, which most explained with inaccurate delivery date predictions at ANC follow ups, mentioned by $30(26.7 \%)$ of the respondents [Figure 2 ]. 
Table 2: showing obstetric related charactertics of mothers $(n=180)$ in Waka town, SNNPR-2020

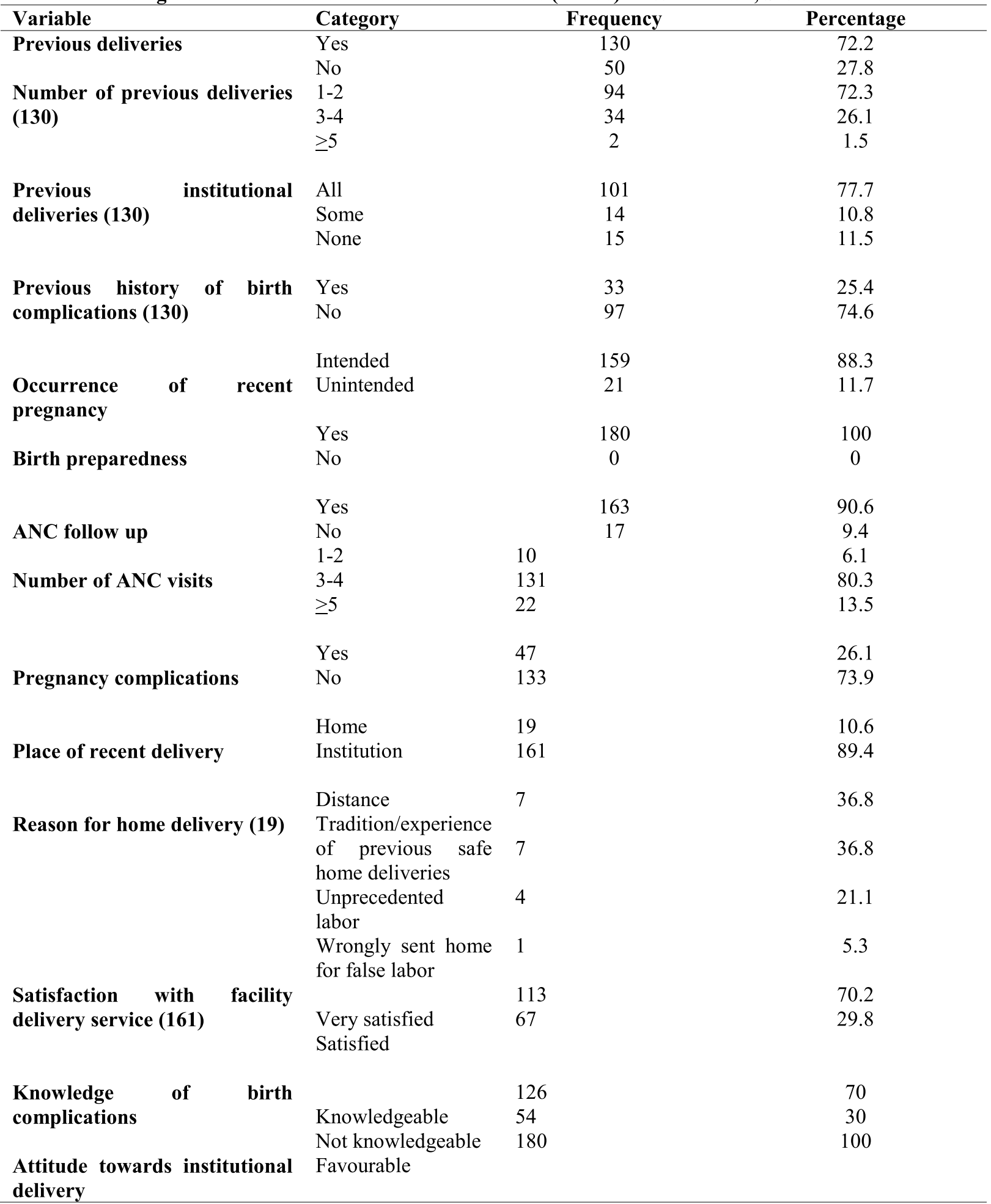




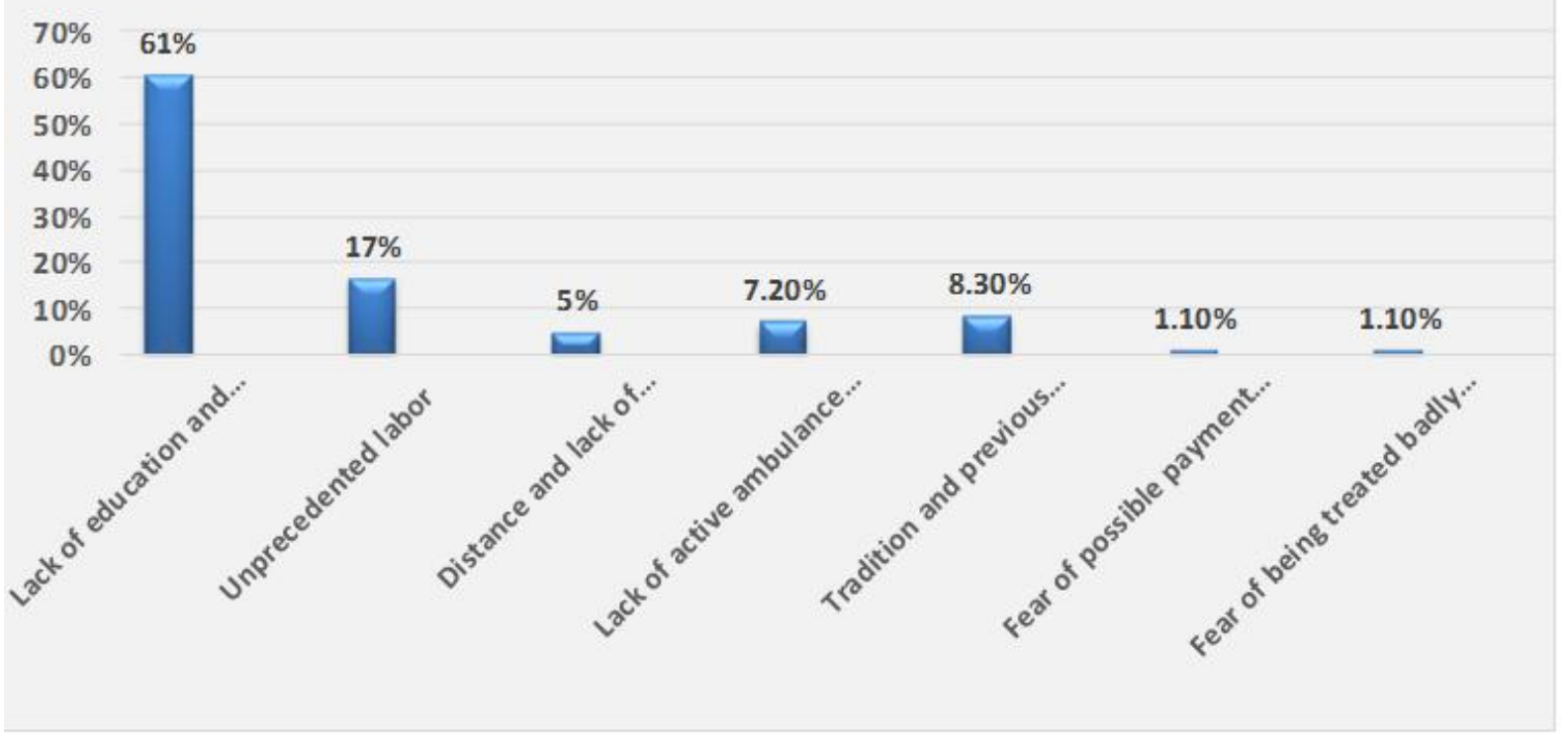

Figure 3: showing response results of open question, on possible reasons behind home delivery in Waka town, SNNPR-2020

\section{Health Service Related Characteristics}

Health institution was accessible within a distance of 30 minutes' walk for $98(54.4 \%)$ of the respondents. And, concerning accessibility of health information sources, $151(83.9 \%)$ of the respondents had access to a television, $113(62.8 \%)$ of the respondents had accesses to a radio, and $34(18.9 \%)$ of the respondents had access to a news letter. Additionally, 173 (96.1\%) of the respondents reported the presence of a Health Extension Worker (HEW) in their area, out of whom; $133(76.9 \%)$ reported having received a Health Education concerning institutional delivery from the HEW, while the rest $40(23.1 \%)$ reported having never received such education. And, out of the women who reported receiving a Health Education concerning institutional delivery, 79 (59.4\%) were very satisfied with the education [Table 3].

Table 3: Showing Health service related factors in Waka town (2020)

\begin{tabular}{|c|c|c|c|}
\hline Variable & Category & Frequency & Percentage \\
\hline \multirow[t]{2}{*}{ Distance time taken to a HI by walking } & $>30$ minutes & 82 & 45.6 \\
\hline & $<30$ minutes & 98 & 54.4 \\
\hline \multicolumn{4}{|l|}{ Television accesses } \\
\hline & Yes & 151 & 83.9 \\
\hline & No & 29 & 16.1 \\
\hline \multicolumn{4}{|l|}{ Radio accesses } \\
\hline & Yes & 113 & 62.8 \\
\hline & No & 67 & 37.2 \\
\hline \multicolumn{4}{|l|}{ Newsletter accesses } \\
\hline & Yes & 34 & 18.9 \\
\hline & No & 146 & 80.1 \\
\hline \multicolumn{4}{|l|}{ HEW } \\
\hline & Present & 173 & 96.1 \\
\hline & Not present & 7 & 3.9 \\
\hline \multicolumn{4}{|l|}{ HE concerning institutional delivery (173) } \\
\hline & Yes & 133 & 76.9 \\
\hline \multirow[t]{4}{*}{ Satisfaction with the $H E$ received } & No & 40 & 23.1 \\
\hline & Very satisfied & 79 & 59.4 \\
\hline & Satisfied & 54 & 40.6 \\
\hline & Not satisfied & 47 & 38 \\
\hline
\end{tabular}


Multivariate Analysis of Factors Associated with Institutional Delivery

Different factors have been identified to have association with utilization of institutional delivery service. On multivariate analysis of the selected factors with institutional delivery; educational, economic and marital status of the mother, spouse occupation, distance time taken, health education provision, Information source availability, intendedness of the pregnancy, ANC follow up, and Knowledge of birth complications were found to be significantly associated.

In this study Married women were found to be 9.3 times more likely ( $\mathrm{OR}=9.3 ; \mathrm{CI}: 1.8-16.4)$ to deliver at a facility compared to unmarried women, women with high income status were 4.9 times more likely, $(\mathrm{OR}=4.922$; CI: 2.0-11.9) and women with medium income were 2.8 times more likely (2.8; CI: 1.3-6.5) than women with low income. Women who had intended pregnancies were found to be 4.8 times more likely (OR=4.8; CI:2.3-10.3) than those with unintended pregnancies, women with government employee husbands were 10.9 times more likely $(\mathrm{OR}=10.9 ; \mathrm{CI}: 4.2-28.5)$ to deliver at a facility than women whose husbands were farmers

Table 4: Multivariate analysis of factors associated with institutional delivery in Waka town, SNNPR (2020)

\begin{tabular}{|c|c|c|c|c|c|c|c|c|}
\hline \multirow[b]{3}{*}{ Variables } & \multicolumn{7}{|c|}{ Place of delivery } & \multirow[b]{3}{*}{$\mathrm{p}$-value } \\
\hline & \multicolumn{2}{|c|}{ At Home } & \multicolumn{2}{|c|}{ At Institution } & \multirow{2}{*}{\multicolumn{3}{|c|}{$\operatorname{AOR}(\mathrm{CI}=95 \%)$}} & \\
\hline & $\mathrm{N}$ & $\%$ & $\mathrm{~N}$ & $\%$ & & & & \\
\hline \multicolumn{9}{|l|}{ Educational status } \\
\hline Illiterate & 6 & 3.3 & 4 & 2.2 & & & & .000 \\
\hline Primary school & 9 & 5.0 & 34 & 18.9 & 5.462 & $(1.812$ & 16.469) & .003 \\
\hline Secondary school & 4 & 2.2 & 73 & 40.6 & 27.551 & $(8.062$ & $94.153)$ & .000 \\
\hline $1^{\text {st }}$ degree and above & 0 & 0 & 50 & 27.8 & & 1 & & \\
\hline \multicolumn{9}{|l|}{ Occupational status } \\
\hline Yes & 13 & 7.2 & 102 & 56.7 & 23.100 & $(7.882$ & $67.703)$ & .000 \\
\hline No & 6 & 3.3 & 59 & 32.8 & & 1 & & \\
\hline \multicolumn{9}{|l|}{ Marital status } \\
\hline Married & 17 & 9.4 & 159 & 88.3 & 9.353 & $(2.238$ & $39.095)$ & .002 \\
\hline Unmarried & 2 & 1.1 & 2 & 1.1 & & 1 & & \\
\hline \multicolumn{9}{|l|}{ Spouse occupation } \\
\hline Government employee & 5 & 2.8 & 91 & 51.7 & 10.920 & $(4.190$ & $28.458)$ & .000 \\
\hline Private worker & 6 & 1.7 & 58 & 33.0 & 5.800 & $(2.288$ & 14.704) & .000 \\
\hline Farmer & 6 & 1.7 & 10 & 5.7 & & 1 & & \\
\hline \multicolumn{9}{|l|}{ Monthly income } \\
\hline Low income & 12 & 6.7 & 30 & 23.3 & & 1 & & \\
\hline Medium income & 5 & 2.8 & 36 & 22.8 & 2.880 & $(1.277$ & $6.496)$ & .011 \\
\hline High income & 2 & 1.1 & 97 & 53.9 & 4.922 & $(2.034$ & $11.91)$ & .000 \\
\hline \multicolumn{9}{|l|}{ distance time taken } \\
\hline$>30$ minutes & 15 & 8.3 & 67 & 37.2 & & 1 & & \\
\hline$<30$ minutes & 4 & 2.2 & 94 & 52.2 & 5.261 & $(2.339$ & 11.836) & .000 \\
\hline \multicolumn{9}{|l|}{ health education provided } \\
\hline Yes & 4 & 2.3 & 126 & 72.4 & 16.293 & (7.101 & $37.383)$ & .000 \\
\hline No & 15 & 8.6 & 29 & 16.7 & & 1 & & \\
\hline \multicolumn{9}{|l|}{ TV access } \\
\hline Yes & 7 & 3.9 & 147 & 81.7 & 18.000 & $(8.379$ & $38.669)$ & .000 \\
\hline No & 12 & 6.7 & 14 & 7.8 & & 1 & & \\
\hline \multicolumn{9}{|l|}{ Occurrence of the pregnancy } \\
\hline Intended & 12 & 6.7 & 143 & 79.8 & 4.873 & $(2.304$ & $10.305)$ & .000 \\
\hline Unintended & 7 & 3.9 & 18 & 9.6 & & 1 & & \\
\hline \multicolumn{9}{|l|}{ ANC follow up } \\
\hline Yes & 6 & 3.3 & 159 & 88.3 & 17.250 & $(5.874$ & $37.965)$ & .000 \\
\hline No & 13 & 7.2 & 2 & 1.1 & & 1 & & \\
\hline \multicolumn{9}{|c|}{ Knowledge of birth complications } \\
\hline Knowledgeable & 4 & 2.2 & 117 & 65.0 & 9.972 & $(4.403$ & 22.584) & .000 \\
\hline Unknowledgeable & 15 & 8.3 & 44 & 24.4 & & 1 & & \\
\hline
\end{tabular}

\section{Discussion}

Among respondents, majority $(89.4 \%)$ delivered their last child in health facility. This result was higher than studies done in different study areas including the previous study which was conducted in Maraka; the wereda containing the current study town (33\%) [10]. It is also higher than the report of the 2019 mini EDHS which 
reported $48 \%$ at country level and $14.9 \%$ for SNNPR region [3], as well as the report of a 2019 study done in Dallocha town SNNPR (74\%) [14].Also higher than studies done in Bench Maji zone SNNPR [15], a study done in Tigray region [16], also a study done in Liben district, Guji zone, Oromia [17], and etc...This high prevalence result may be attributed to the increased attention given to home deliver reduction by the town health center and the increased deployment of HEWs in the society, with strict supervision by the health center.

In this study concerning spouse occupation, women with spouses who were government employees were 9.8 times more likely to deliver at a facility than women with farmer husbands, which is higher than what was reported by Birhanu Butas thesis report, which states 5.2 times likelihood [14]. Educational status of the women was another major associated factor, as shown in this study women with educational level of primary school and secondary school were when compared with illiterate women, similarly higher likelihood of educated women was reported in the 2019 mini EDHS, and the same association was reported by many other studies too [18-19, 20, 3, 21-22, 23]. Regarding economic status, the high income level were almost 5 times more likely, and the middle classes were almost 3 time more likely than the low income achiever women, which again goes along with the report of the 2019 mini EDHS [3].

Conclusion: Institutional delivery services in Waka town was shown to be relatively better compared to other studies in the region and in Ethiopia even though it is still below the Health Sector Transformation plan of Ethiopia to increase skilled delivery to $90 \%$ by $2019 / 20$. In this study educational, economic and marital status of the mother, spouse occupation, distance time taken, health education provision, Information source availability , extendedness of the pregnancy, ANC follow up, and Knowledge of birth complications have shown significant association with institutional deliver service utilization.

\section{References}

1.United Nations. The Millennium Development Goals Report. UN; 2015.

2.UNICEF. Healthy Mothers, Healthy Babies: Taking stock on maternal health. UNICEF; 2020.

3.EPHI and ICF. Ethiopian mini Demographic and Health Survey 2019. EPHI; 2019.

4.Hadis M, Dibaba A, Ababor S, Assefa Y. Improving skilled birth attendance in Ethiopia (SURE policy brief). Addis AbabaEthiopia: Ethiopian Public Health Institute; 2014. Available from: www.evipnet.org/sure $[18 / 5 / 2020]$.

5.Andersen R, Newman J. Societal and Individual Determinants of Medical Care Utilization in the United States. The Milbank Quarterly. 2005; Vol.83: 1-28.

6.Masresha A, Robera O, Ayanos T, Tefera B.Institutional delivery service use and associated factors among women who delivered during the last 2 years in Dallocha town, SNNPR, Ethiopia. Nursing Open. 2019: 188193.

7. Solomon W, Amare K, Mengistu W. Utilization of institutional delivery service and associated factors among mothers in North-West Ethiopian. BMC research notes. 2018: 2-5.

8.Zerihun T, Tizta T, Misra. Male Involvement on Skilled Delivery Care Utilization in Maraka Wereda, Southern Ethiopia: A Community Based Cross Sectional Study. Science PG.2015: 700-704.

9.Lelisa S, Melkamu B, Yusuf A. Maternal and newborn health services utilization in Jimma Zone, Southwest Ethiopia: a community based cross sectional study. BMC pregnancy and child birth. 2019: 4-10.

10.Canavan, A. Review of global literature on maternal health interventions and outcomes related to skilled birth attendance. KIT Working Papers Series. 2009: 6-7.

11.Sanni Y, Ghose B, Michael E. Factors associated with maternal utilization of health facilities for delivery in Ethiopia. Royal Society of Tropical Medicine and Hygiene.2018: 312-316.

12.Tesfay G, Miguel S, Kerstin E, Isabel G. The Health Extension Program and its association with change in Utilization of Selected Maternal Health Services in Tigray Region, Ethiopia: A Segmented Linear Regression Analysis. PLOS ONE. 2015: 6-12.

13.Zeleke A, Wondwossen T, Tesfay G. Multilevel analysis of individual and community level factors associated with institutional delivery in Ethiopia. BMC research notes. 2015: 3-8.

14. Brehanu B.Factors associated with delivery care among women of reproductive age in Oromia, Ethiopia. Addis Ababa Ethiopia: Addis Ababa University of Graduate studies; 2018.p. 21.

15. Niguse T, and Tafesse L. Utilization of institutional delivery service and associated factors in Bench Maji zone, Southwest Ethiopia: community based cross sectional study. BMC health services research. 2017: 3-8.

16. Tesfay G, Miguel S, Kerstin E, Isabel G. The Health Extension Program and Its Association with Change in Utilization of Selected Maternal Health Services in Tigray Region, Ethiopia: A Segmented Linear Regression Analysis. PLOS ONE. 2015: 6-12.

17. Wako G, Dejene H. Institutional delivery service utilization and associated factors among women of reproductive age in the mobile pastoral community of the Liban District in Gujji Zone, Oromia, Southern Ethiopia: a cross sectional study. BMC pregnancy and child birth. 2017: 3-9.

18. Mihiretu A, Tadele D, Mengistu M, Institutional Delivery Service Utilization among Women from Rural 
Districts of Wolaita and Dawro Zones, Southern Ethiopia; a Community Based Cross-Sectional Study. PLOS ONE. 2016: 4-9.

19. Zerihun T, Tizta T, Misra. Male Involvement on Skilled Delivery Care Utilization in Maraka Wereda, Southern Ethiopia: A Community Based Cross Sectional Study. Science PG.2015: 700-704.

20. Adane N, Telake A, Mezgebu Y. Institutional Delivery Service Utilization and Associated Factors in Ethiopia: A Systematic Review and Meta-Analysis. BMC pregnancy and childbirth. 2019: 10-16.

21. Brehanu B. Factors associated with delivery care among women of reproductive age in Oromia, Ethiopia. Addis Ababa Ethiopia: Addis Ababa University of Graduate studies; 2018.p. 21.

22.Niguse T. and Tafesse L. Utilization of institutional delivery service and associated factors in Bench Maji zone, Southwest Ethiopia : community based cross sectional study. BMC health services research. 2017: 3-8.

23.Biresaw W, Shegaw Z. Compassionate and respectful maternity care during facility based child birth and women's intent to use maternity service in Bahir Dar, Ethiopia. BMC pregnancy and childbirth. 2018: 3-8.

24.Luelseged A, Mussie A, Ayal D. Magnitude of institutional delivery service utilization and associated factors among women in pastoral community of Awash Fentale district Afar Regional State, Ethiopia. BMC research notes. 2018: 2-5.

25.Biresaw W, Shegaw Z. Compassionate and respectful maternity care during facility based child birth and women's intent to use maternity service in Bahir Dar, Ethiopia. BMC pregnancy and childbirth. 2018: 3-8.

26.Eskezaiw A, Abdu S, Getnet G. Association between antenatal care follow-up and institutional delivery service utilization: analysis of 2016 Ethiopia demographic and health survey. BMC public health. 2019: 3-5.

27.Sanni Y, Ghose B, Olalekan A. Why some women fail to give birth at health facilities: A comparative study between Ethiopia and Nigeria. PLOS ONE. 2018: 4-9.

28.CSA and ICF. EDHS 2016.CSA; 2016.

29.United Nations. The Millennium Development Goals Report.UN; 2015. 